in several cases within my own knowledge, have rendered the child hideous for months, incurable, or only cured at the expense of life itself."

It is only a short time since we read with grief and astonishment, statements made in the House of Com. moas by a member of our own profession, denouncing the discovery of the immortal Jenner in terms as illogical, unscientific, and as superstitiously prejudiced, as those of the Poor-law guardian just quoted. I have reason to know that amongst the profession in this town there are some who, although fully appreciating the value and importance of vaccination, and whose opinions are entitled to every consideration, nevertheless, are not altogether satisfied upon this point; nor should we, I think, be surprised to find this to be the case, as it must be admitted that appearances often favour the idea. Most medical men, especially those who practise extensively amongst the poorer classes, will remember instances in which patients are brought to them suffering from various diseases supposed to be produced by "bad matter." This notion, erroneous as I believe it to be, frequently proves a source of much annoyance and anxiety to a conscientious medical attendant; while, at the same time, it is injurious to the cause of vaccin. ation, by lessening the confidence of the public in its safety. It is, therefore, highly desirable to remove, if possible, any doubt or misgiving which intelligent practitioners may entertain upon the subject. It would be impossible, in the limits of this paper, to give even a condensed account of the conclusive evidence which experiment and investigation have brought to bear upon this disputed point. I would earnestly recommend those interested in the question to peruse carefully the interesting and important statements given by Mr. Simon in his report on this particular branch of the subject; it is there fully and dispassionately discussed, and, to my mind, as satisfactorily disposed of as can be expected in any case upon which negative evidence alone can be brought to bear.

I may, perhaps, be permitted briefly to state one conclusion to which Mr. Simon arrives; namely, that lymph taken from a true Jennerian vesicle at the proper period of its development is incapable of producing any other disease except cow-pock; and this fact, says Mr. Simon, rests upon "one simple mass of evidence, which, to my mind, seems conclusive. It has been proved, on a large scale, that vaccine lymph taken from persons actually suffering from small-pox conveys to those who are vaccinated with it no other than the vaccine infection." (Blue Book, p. 68.) In reference to scrofula and most skin diseases, it is well known that, even when for ex. periment their specific discharges and other products are deliberately inoculated on the healthy, they are absolutely incommunicable by contagion; and it is incon. ceivable that the vaccine lymph, even if it could include these products, would alter the essential condition of their nature. As to those diseases whose specific products are infectious, the question arises whether the constitutional existence of such diseases can qualify the contents without modifying the characteristic development of a true Jennerian vesicle; and this question has been conclusively answered in the negative by experi. ment on an extended scale. He sums up his voluminous statements by observing, "Obviously, then, one, at least, of two conclusions is inevitable. Either it is the case that, even with reprehensible carelessness as to the source of lyrnph, vaccination (so long as, in any sense of the word, it is vaccination) cannot be the mears of communicating any second infection; or else it is the case that, in the world of vaccinators, care is almost universally taken to exclude that possibility of danger."

The mode of preserving lymph adopted here is almost exclusively by charging ivory points and carefully drying them. In this state, it is probable that vaccine lymph will retain its infective power as long as in any of the various methods which have been suggested. It has, as is well known, been successfully practised for many years by the National Vaccine Establishment, and distributed to all parts of the world. It is very convenient for transmission; and is well adapted for the purpose wherever a large supply is required, and where it becomes, in consequence, an object to economise the lymph, and the time occupied in obtaining it. A larger number of effective charges can be taken from a given number of vesicles by means of the ivory points than in any other way.

The very prevalent custom of preserving lymph be. tween two small squares of glass is attended with this serious objection that, as the lymph is thus kept in a moist state, it is, like all organic fluids, extremely liable to undergo decomposition, and then, instead of producing a vaccine vesicle, it is liable to be followed by the in jurious effects of a putrid secretion. Fatal instances of this unfortunate result have been met with by Mr. Marson. The same objection applies even more strongly to the plan of keeping lymph upon the glass tongue of the stoppered bottles used for the purpose. In warm weather, a few hours will sometimes suffice to cause the decomposition of the lymph ; and the variable and uncertain period during which it remains unchanged, only adds to the danger. With the hermetically sealed glass tubes of Dr. Husband, it is possible that the fluid may retain its properties for a nuch longer period; but with them there is a certain risk, especially if, by oversight, the tube should not be perfectly closed. In the dry state, as on the ivory points, the lymph may lose its power of infecting by lapse of time, and cause disappointment; but the risk of mischief from putrescence or decomposition appears to be altogether avoided, which is, undoubtedly, the greater evil of the two.

\section{INTRACTABLE CASE OF NEURALGIA CURED BY OXYGEN.}

By JoHn Hooper, M.D., M.R.C.P., Hoddesdon, Herts.

I READ with much attention and satisfaction Dr. Birch's excellent paper on Oxygen as a Therapeutic Agent; giving the great experience he has had in the treatment of cases with this remedy. Moreover, I am convinced that nothing contributes so much to the improvement of health generally, to the augmentation of the power of enduring mental and physical exertion, as removing to such localities as are deemed healthy; viz., abounding in oxygen. It hence appears an argumentum ad judicium that, by inhaling a larger amount of oxygen, especially upon a graduated scale, in proportion to the capability of the patient to bear it, many diseases might be cured, which are at present considered incurable. We have heard much lately of the brain-power being sustained and improved by alcoholic stimulants; but will not this be attained more efficiently by inhaling atmospheric air, exuberant in oxygen? What enabled Sir Francis Head to endure such an amount of exertion in his gallop across the Pampas, South America? What caused such exhilaration of spirits, and such an amount of endurance without fatigue? Clearly, the advantage of breathing an atmosphere free from contamination, abounding in oxygen. It has been observed by the celebrated Liebig, that vital power is dependent upon the mutual action of oxygen and the elements of food.

About twenty-five years ago, $I$ had an opportunity of witnessing the successful effect of inhaling oxygen in a case of asthma.

$\mathrm{J}-\mathrm{L}-$, aged 55 , had for many years been a martyr to asthma before this attack, under which he was then labouring in the year 1835-36, when it was attended with extreme danger. In one of the morning paroxysms, he was thought by all around him to be 
dying. It appearea to me impossible that he could rally: his death was a question of moments. As a dernier ressort, I determined to try oxygen. The means of making it were at hand. The end of a glass retort was applied to his mouth, through which undiluted oxygen was passing. $\mathrm{He}$ had not the power at first to enclose it with his lips. The effect was wonderful, and quickly manifest, in increased mobility of the ribs; fuller in. spiration; disappearance of the lividity of the cheeks; and, lastly, in his seizing the end of the retort; and in the avidity with which he inhaled when possessing the voluntary power. Indeed, fearing he would have too much, I was obliged to pull it away. He soon became convalescent, and is still alive,

I am not fond of new-fangled remedies; but Dr. Birch has demonstrated to the medical public in very forcible and convincing language, that the administration of $x x y$ gen is an invaluable means of contending with disease especially of an intractable character. I therefore resolved to call on Mr. Barth of Piccadilly, who is the inventor and manufacturer of the pneumatic apparatas. $\mathrm{He}$ very politely gave me all the information required. I forthwith ordered one to be made for me. This instrument has been in use about two years; it answers exceedingly well. I have several cases to communicate; but the triumphant and rapid effect of oxygen was so manifest in this most trying case, that $I$ am induced to give it the first publicity.

Feb. 1860. I was requested by Mr. Horley, surgeon, of this place, to see $\mathrm{Wm} . \mathrm{R}-$, aged 40 , who had been five months under his care, suffering from severe pain in his right foot. The pain during the early period of his attendance never left the patient; it was accompanied with aggravated paroxysms; the whole foot was exceedingly hot. Cold saturnine lotions afforded some relief if constantly applied. Mr. Horley gave him quinine and narcotics, with only partial relief, while under his care. He considered it a most unsatisfactory case. I examined the foot carefully; it was now quite cold, and rather blue; he was no longer troubled with the excessive heat of the part. The pain was very inteuse-extending over the whole sole of the foot to the toes, and on the sides over the instep, following the course of the tibial nerve from the internal ankle, through the notch in the os calcis to the division of this nerve, and along the internal and external plantar branches. He had always pain, attended by frequent excruciating paroxysms; the slightest pressure on movement of the foot so augmented his sufferings that he groaned, and occasionally screamed from the intoler. able agony. The pulse was natural; the bowels were regular. The feet were very flat, with scarcely any arch; therefore the plantar nerves were little protected from pressure. It had been a portion of his duty to carry heavy weights on his shoulders for several weeks anterior to this attack, which he considered to be the pro. bable cause. I ordered a blister of the size of a shilling to be applied over the part where the tibial nerve bifur cates, and to remain on twenty-four hours; the epider. mis was to be removed, and a powder, consisting of a grain of acetate of morphia and three grains of compound tragacanth powder, to be sprivkled over the denuded surface night and morning. A quarter of a grain of extract of belladonna was ordered to be given three times daily, the dose to be increased every seventh day until he cuuld take one grain three times a day. Think. ing there might be some irritation of the medulla ob longata, I ordered a blister to be applied to the nape of the neck, and the discharge to be kept up for three weeks. Under this plan, the tenderness became less, and the paroxysmal pain more tolerable from day to day, until he was perfectly free.

April 2nd. He was quite well; and for ten or twelve days had been able to walk about seeking employment. April 22nd. I was informed he was almost as bad as ever, in consequence of having walked several miles in one day.

About May 1st, he was admitted into University Col. lege Hospital, London, where he remained about seven weeks. Numerous external and internal appliances were used experimentally, to afford relief, with varied consequences. Among them were two or three applications of blisters to the instep. Great attention was paid to his diet and general health, under which treatment he became somewhat better; and the physician under whose care he had been expressed his sorrow that he could do no more for him, and said it would be well to return to the country. He would provide him with medicine, which he could continue to take on reaching home. He did return, and I again saw him after a few days. Although the intervals of ease were longer, the paroxysms were very severe. He continued the remedies ordered by the hospital physician until October 30 th, when I heard he was much worse-indeed, suffering as much as when first under my eare in February. He obtained admittance into St. Thomas's Hospital about November 15 th, where he continued six weeks. Numerous blisters were applied to the sole of the foot, without affording relief; the reapplications were continued nearly the whole time he was there. Other plans were adopted, equally unavailirg. He left decidedly worse than when he entered.

Jan. 20th, 1861. I was requested to see him. He was in a most lamentable state; the pain was excruciating in the extreme. He said that, ever since the blisters healed, the skin had felt tight like a bandage, which aggravated the pain. There was no cessation to lis sufferings. He pointed to a spot over the internal plantar nerve, and thought there was something which pricked him, and wished me to cut it out. I examined carefully, and could not discover the presence of any foreign body. He could not bear the foot in a pendulous position; he was obliged to creep up stairs to his bed on his hands and knees, but the effort to do so aggravated the pain so much that he screamed loud enough to be heard far from his cottage. His agony was beyond description. I have been in the profession forty-seven years, and never knew any one endure so much pain. Unless there was some remedy, he must. have sunk. For the purpose of relaxing the skin and relieving pain, I ordered a strong lotion of belladonna covered with oiled skin; this was continued a whole week; it was then removed. The feeling of a bandage no longer existed. I ordered two leeches to be applied to the part in most pain; this gave him so much ease that he repeated the application several times. Strong anodyne doses were administered twice or thrice daily.

Feb. 1st. The poor fellow's sufferings were so extreme that he was disheartened and inconsolable. I now determined to try the effect of inhaling oxygen. This appeared to be one of those cases in which Dr. Birch would have tried the therapeutic agency of this element ; viz., "diseases otherwise incurable, eminently dangerous, or very intractable." His pulse was small and weak; he had no appetite; very little sleep; he was very pale, and exceedingly attenuated. The urine was clear.

Feb. 4th. By means of Barth's apparatus for portahle oxygen gas, the oxygen was administered in the proportion of one part of oxygen to eight of atmospheric air. After inhaling two gallons in five inspirations, at intervals of five and ten minutes, his pulse became fuller and stronger; his spirits were improved; he had less pain. After the first inspiration, the blood began to mantle his cheeks.

Feb. 5th. After yesterday's inhalation, he had little pain until bedtime; but during the night and following morning the pain had been very severe. The urine was greater in quantity, very turbid, loaded with urates and phosphates. 
Feb. 6th. He had been almost free from pain. The urine was turbid; his pulse was stronger; the appetite was improved.

Feb. 7th. He could bear pressure on the affected part; had no pricking sensation; he was almost free from pain.

Feb. 8th, 9th, 10th. Oxygen was used daily since the 7th. He had been free from pain. The health had been daily improving, and the appetite was excellent.

Feb. 26th. Since the 10th, oxygen had only been used every other day. He was perfectly well.

Feb. 7th, 1862. Wm. $\mathrm{R} \longrightarrow$ has been quite free from any ailment since February 1861 ; and during the larger portion of the time he has been able to follow his usua vocation as a labourer.

\section{CASE OF MAMMARY CANCER: REMOVAL RELAPSES.}

By Francis Troup, Esq., Auchtermuchty, Fife.

About the middle of December, 1858, I was requested to see H. A., aged 45, unmarried. Sixteen months previously, when washing herself, she noticed that the lef nipple was retracted; and, on handling the breast, felt it hard and heavy. This did not disturb her till twelve months afterwards, when the skin of the areola began to ulcerate, and thereafter, the whole breast to become the seat of frequent lancinating pains. A medical man was then consulted; and poulticing with the bruised leaves and stalks of Stellaria media was recommended. The ulceration spread, and the darting pains increased, despite this treatment; and when I saw the diseased mamma for the first time, it presented the following appearances.

Within a circle of two inches diameter-the centre of which was the much retracted nipple-the skin of the left breast was excavated by a chuin of small ulcerations, with hard and everted edges, surfaces discharging thin pus, and bleeding from the slightest touch. The periphery of the ulcerations was surrounded by swollen and purplish-red integument; and, exterpally still, for another half inch, the skin, particularly on the upper aspect of the mamma, was firmly adherent to the parts below. The whole gland was hard and stony, not knobbed, and could be freely moved over the pectoral muscle. In the axilla, a cluster of similarly hard and mobile glands coula easily be felt. The patient, a person of lively disposition and great moral courage, had but little of the green-yellow complexion of malignant disease. She menstruated regularly; her pulse was rapid; and her appetite had only lately begun to fail. There was no history of ancestral cancer or consumption; both parents had lived to very old age; and one sister had died of typhus.

The patient was anxious to be rid of the disease, and willingly accepted all risks, immediate and future. Accordingly, assisted by Dr. John Lyell of Newburgh and his son, on December 29th, 1858, I operated. Incisions, forming a broad oval and traced in sound skin, were made round the diseased mass, and the dissection was carried down to the digitations of the pectoralis, a part of which was cut away, as it was incorporated with the tumour, and the disease thus cleanly removed. Many vessels sprang; but were merely closed by torsion. The flaps, with a great deal of straining at their sterral half, were approximated by seven silver wire sutures. Adaptation was perfect, save at the three most sternal sutures; there the incisions met only where the stitches were tied. The axillary glands were then dissected out. A fold of skin was pinched up, as in herniotomy, the knife run through it, and the indurated glands hooked up with a tenaculum, and, chiefly by tearing, removed. In four weeks the whole incisions had closed.
The parts removed weighed one pound. When cut into, the tumour was crisp and resistent. 'The cut surfaces in the neighbourhood of the nipple were veined with radiating white-blue bands: elsewhere they were yellowish, and flecked here and there with arborescent deeper yellow streaks. The first section disclosed three or four cavities of the size of peas, filled with semifluid glistening matter, which the microscope shewed to consist of exceedingly numerous crystals of cholesterine, molecules, oil-globules, and brown-black granule cells and masses. The solid matter composing the yellow streaks could be picked out in nodules; these, when crushed and examined, consisted of free nuclei, fatty cancer-cells, free fat, granule-cells, and more rare cho. lesterine-crystals. Hence, probably the cavities seen on section were originally the site of nodules of the yellowish matter-the so-called reticulum-whose cell-elements, having undergone fatty degeneration and disintegrated, so left the cavities. The surfaces of all the sections made soon bedewed themselves with a dirty white fluid, which consisted of granule-masses, oil. globules, and cells, round, oval, oblong, and caudate, with nuclei, varying in number from one to five; the more spherical cells almost invariably only containing one, which then nearly filled the envelope. Save on the pectoral aspect of the tumour, sections made with Valentin's knife shewed little trace of filaments; but in that quarter they were numerous, interlacing confusedly among the cell-elements, or forming band-like trabeculæe, the interstices of which were stuffed with largely nucleated round and oval cells. Sections of the axillary glands shewed the same absence of fibres and more common fusiform and caudate cells, including secondary ones; no reticulum nor cavities. On removing the areolar tissue and fibres of the pectoratis from the under aspect of tumour, its surface was seen to be bossed with cysts tensely filled, so that the fluid contents squirted out on puncture. These cysts were as large as a hazel-nut, or as small as a pea. The fluid in every one opened was amber-coloured, and slightly glutinous: that of the smaller ones contained no cellforms, but was finely molecular-the molecules being soluble in ether; that of the larger presented, first, abundance of very finely granular, or homogeneous and transparent, uninucleated, round, and cylindrical cells, varying in size from 3-7000ths to 12-7000ths of an inch; and also, aggregated patches of cylinder cells in single stratum. Acetic acid caused some precipitation or coa. gulation in the interior of the isolated cells; for they became darker and coarsely granular under its action. The walls of the cysts were composed exteriorly of con. nective tissue, with numerous spiral and anastomosing fibres of various degrees of fineness, interpenetrating it; internally, of cylindrical epithelium in single layer; the aggregated patches of cells seen floating in the fluid contents of the larger cysts being, doubtless, detached portions of this lining.

For more than a yeur, the patient remained free from disease, but at last it returned in the arm-pit. The lump there was, in February 1860, of the size of a small egg. As her sufferings were severe, she wished again to be operated on; and this time, I enucleated the tumour by M. Maisonneuve's plan of circular cauterisation. The base of the swelling was circumscribed by seven or eight punctures with a bistoury, and when the knife was withdrawn, a like number of tlat conical arrows, made of Canquoin's paste, were pushed into the openings so made. In a few hours, the mass thus isolated was dead; and in ten days had sloughed out, leaving a healthy sore, which rapidly filled up, and I had again the satisfaction of seeing my patient free from pain. But in fire or six months, the old induration was again begun; and now, December 23rd, 1861, the axilla is one large open ulcer. As yet, the mammary cicatrix is sound (three years after operation); but at its sternal extrenity thero 